\title{
Role of Reproductive Factors in Hepatocellular Carcinoma: Impact on Hepatitis B- and C-Related Risk
}

\author{
Ming-Whei Yu, ${ }^{1}$ Hung-Chuen Chang, ${ }^{1}$ Shun-Chiao Chang, ${ }^{1}$ Yun-Fan Liaw, ${ }^{2}$ Shi-Ming Lin, ${ }^{2}$ Chun-Jen Liu, ${ }^{3}$ \\ Shou-Dong Lee, ${ }^{4}$ Chih-Lin Lin, ${ }^{5}$ Pei-Jer Chen, ${ }^{3}$ Shee-Chan Lin, ${ }^{6}$ and Chien-Jen Chen ${ }^{1}$
}

Hepatocellular carcinoma (HCC) is more prevalent in men than in women. Estrogen may play some role in the development of HCC. We conducted a multicenter case-control study to evaluate the effects of reproductive factors on HCC risk, and to assess whether the association between each factor and HCC differs between hepatitis B surface antigen (HBsAg)-positive and -negative women, in which hepatitis $\mathrm{C}$ virus (HCV) is the major cause of HCC. The study included 218 women with HCC and 729 control women selected from nonbiological and firstdegree female relatives of patients with HCC. The risk of HCC was inversely related to the number of full-term pregnancies $($ FTP $)\left(P_{\text {trend }}=.0216\right)$ and age at natural menopause $\left(P_{\text {trend }}=\right.$ .0251 among women aged 45-55 without prior surgical menopause). Oophorectomy at age $\leq 50$ during premenopausal years was also a risk factor (multivariate-adjusted OR, 2.57; 95\% CI, 1.42-4.63). Use of hormone replacement therapy (HRT) (multivariate-adjusted OR, 0.46; 95\% CI, 0.27-0.79) was associated with a lower risk of HCC, and there was a trend in the risk with increasing duration of HRT $\left(P_{\text {trend }}=0.0013\right)$. All reproductive factors had a similar impact on HBsAg-positive and -negative women except for an early menarche ( $\leq 12 \mathrm{vs.} \geq 16$ years), which increased HCC risk in HBsAg carriers (multivariate-adjusted OR, 6.96; 95\% CI, 2.52-19.18) but posed no increased risk in noncarriers $\left(P_{\text {interaction }}=.0053\right)$. In conclusion, increased exposure to estrogen during adulthood may provide a protective effect against HCC. Nevertheless, an early menarche, which results in early estrogen exposure, does not confer protection for HBsAg carriers. (HePATOLOGY 2003;38:1393-1400.)

$\mathrm{H}$ epatocellular carcinoma (HCC) is a highly malignant disease characterized by a striking male predominance; the male-to-female ratios in the incidence of HCC range from 2 to 4 in geographically diverse populations. ${ }^{1,2}$ This gender difference may be, at

Abbreviations: $H C C$, hepatocellular carcinoma; $H B V$, hepatitis $B$ virus; $H C V$, hepatitis $C$ virus; $H B s A g$, hepatitis $B$ surface antigen; FTP, full-term pregnancy; $H R T$, hormone replacement therapy.

From the ${ }^{I}$ Graduate Institute of Epidemiology, College of Public Health, National Taiwan University; ${ }^{2}$ Liver Research Unit, Chang-Gung Memorial Hospital, ChangGung University; ${ }^{3}$ Hepatitis Research Center, National Taiwan University Hospital; ${ }^{4}$ Department of Medicine, Veterans General Hospital and School of Medicine, National Yang-Ming University; ${ }^{5}$ Division of Gastroenterology, Department of Internal Medicine, Taipei Municipal Jen-Ai Hospital; and ${ }^{6}$ Division of Gastroenterology, Department of Internal Medicine, MacKay Memorial Hospital, Taipei, Taiwan.

Received April 7, 2003; accepted September 5, 2003.

Supported by grants NSC 89-2314-B-002-372 and NSC 90-2320-B-002-181 from the National Science Council and by grant DOH 89-TD-1130 (Frontier Medical Genomic Project) from the Department of Health, Executive Yuan, Taiwan.

Address reprint requests to: Ming-Whei Yu, Graduate Institute of Epidemiology, College of Public Health, National Taiwan University, No. 1 Jen-Ai Road, Sec. 1, Rm. 1550, Taipei 100, Taiwan. E-mail: mingwhei@ha.mc.ntu.edu.tw; fax: (886) 2-23511955.

Copyright (C) 2003 by the American Association for the Study of Liver Diseases. 0270-9139/03/3806-0012\$30.00/0

doi:10.1016/j.hep.2003.09.041 least in part, attributable to differences in exposure to lifestyle risk factors for HCC, such as alcohol consumption and cigarette smoking. ${ }^{3,4}$ However, sex hormone and X-linked genetic factors may also be important.

Estrogen receptors exist in both mammalian and human livers. ${ }^{5-8}$ In experimental rats and mice, there is also a greater preponderance of HCC in male subjects compared with female subjects. This sex difference has been observed in various animal models, including transgenic mice expressing hepatitis $\mathrm{B}$ or $\mathrm{C}$ viral proteins. ${ }^{9-15}$ In addition, ovariectomy in mice increased susceptibility to chemically induced hepatocarcinogenesis. ${ }^{11,16}$ Although these observations may suggest some role for endogenous estrogen in the etiology of HCC in humans, these aspects received relatively scant attention. ${ }^{17-19}$

Exogenous estrogen use may also be associated with the risk of HCC. Several case reports have described the occurrence of liver adenomas or focal nodular hyperplasia in women taking oral contraceptives, ${ }^{20}$ and the possible association between use of oral contraceptives and the risk of HCC has been assessed in several studies. ${ }^{3,17,21-27}$ However, most of these studies were based on a very limited number of case subjects, and the results have been incon- 
sistent. Moreover, the effect of long-term treatment with estrogen on hepatocarcinogenesis in animals is controversial. ${ }^{16,28-33}$

This study reports on associations between reproductive events and exogenous estrogen use and HCC, as observed in a multicenter case-control study of women in Taiwan, where HCC is endemic. ${ }^{1,2}$ An attempt is made to assess the heterogeneity of associations for the risk of HCC in relation to chronic infection with hepatitis B virus $(\mathrm{HBV})$ and hepatitis $\mathrm{C}$ virus $(\mathrm{HCV})$, which are the most important determinants of the disease. ${ }^{1,2,34}$

\section{Patients and Methods}

Study Population. Subjects in this study were a subset of women enrolled in our ongoing genetic epidemiology study of HCC, which was initiated in 1997.35 Eligibility in the current study was limited to women aged 35 years or over because the onset of HCC among women is usually after the age of 35 years and the prevalence of certain reproductive events, such as natural menopause and surgical menopause caused by bilateral oophorectomy, among these women is sufficiently high. The genetic epidemiology study is being conducted in two phases: phase 1 focuses on the comprehensive recruitment of proband patients with HCC, and phase 2 ascertains family members of selected proband patients based on their HBV surface antigen ( $\mathrm{HBs} A \mathrm{Ag}$ ) status and family history of HCC for clinical evaluation (including ultrasonography measurements and conventional liver function tests), biospecimen collection, and questionnaire interview. The protocol was approved by the ethics committee at the College of Public Health, National Taiwan University. Written informed consent was obtained from each subject.

Women diagnosed with incident HCC on the basis of either positive histologic findings or an elevated serum $\alpha$-fetoprotein level ( $\geq 400 \mathrm{ng} / \mathrm{mL}$ ) combined with at least 1 positive image on the angiography, sonography, and/or computed tomography were identified from 4 major hospitals (Chang-Gung Memorial Hospital, Taipei Veterans General Hospital, National Taiwan University Hospital, and MacKay Memorial Hospital) in northern Taiwan. During the hospital stay, each case subject was personally interviewed based on a structured questionnaire and was asked to provide a $10-\mathrm{mL}$ blood sample or a buccal brush sample. Initially, collection of questionnaire data was restricted to information on demographic factors; medical history; health behaviors such as cigarette smoking, alcohol consumption, and dietary intake; and family history of chronic liver disease and cancer. In August 1998, the questionnaire interview was expanded to include an assessment of reproductive history and exposure to exogenous female hormones. There were 231 eligible case patients ascertained between August 1998 and June 2001; $13(5.6 \%)$ refused to cooperate. A total of 218 case patients remained available for analysis in this study.

Controls were selected from HCC proband patients' female relatives who were free of diagnosed HCC and participated in our ongoing genetic epidemiology study of HCC for phase 2 investigation between August 1998 and July 2001. At the time of recruitment, these relatives were administered the same risk factor questionnaire as that administered to the case subjects by trained research assistants. Except for 4 eligible female relatives without available questionnaire data, all proband patients' female relatives eligible for the study were included as controls. The controls consisted of 565 first-degree relatives (women at high risk) of patients with HCC (including 5 relatives of female case patients included in this study and 560 relatives of other patients, largely male patients) and 164 nonbiological relatives who were sampled from spouses (spouse controls) of male patients with HCC and male first-degree relatives who were brothers and sons of patients with HCC.

Serologic Tests. For 210 cases, data on the status of serum HBsAg and/or anti-HCV were abstracted from the medical charts. For 6 cases for whom no information on the status of $\mathrm{HBsAg}$ and anti-HCV were recorded in medical charts and for all the controls with available blood samples, the two viral seromarkers were tested by enzyme immunoassay kits obtained from General Biologicals Corp, Hsinchu, Taiwan. To evaluate whether the sensitivity and specificity of the kits produced in Taiwan are comparable with Abbott's enzyme immunoassay kits (Abbott Laboratories, North Chicago, IL), a random sample of 100 of the controls was selected to test for both viral seromarkers with Abbott's kits. The results from using 2 kinds of kits were found to be completely concordant.

Data Analysis. A subject was classified as postmenopausal if there had been no menstrual period for at least 6 months before the time of interview. Although there would be almost no postmenopausal women among women under age 45 , there would be no premenopausal women among women aged 55 years and older. We therefore analyzed the association between natural menopausal status and HCC only among women aged 45 to 55 years at recruitment who had no history of surgical menopause. In analyses pertaining to the effect of reduction in endogenous levels of estrogen caused by unilateral or bilateral oophorectomy during premenopausal years on the risk of HCC, only oophorectomy performed at age $\leq 50$ was classified as the exposed group because a bilateral oopho- 
rectomy at older ages in premenopausal women was not associated with any reduction in risk of breast cancer, in which estrogen is a causative factor. ${ }^{36}$ A pregnancy was defined as full term if it resulted in a live-born child or a stillbirth.

Tests for differences in the frequency distributions of categorical variables were conducted by the $\chi^{2}$ test. A $t$ test was applied to compare the means of continuous variables between groups. ORs and CIs were calculated by unconditional logistic regression with adjustment for potential confounding factors. Because age and history of diabetes are putative risk factors for $\mathrm{HCC}$ and have been associated with sex steroid hormonal factors, 3,37 all models were adjusted for age at recruitment (continuous variable) and a history of diabetes. Other covariates were included in the multivariable models if their inclusion caused the agediabetes-adjusted ORs to change by more than 10\%.

Potential confounders that were evaluated included age at menarche ( $\geq 16,14-15,13$, or $\leq 12$ years); number of full-term pregnancies (FTP) $(\leq 1,2,3$, or $\geq 4)$; number of failed pregnancies, including miscarriages, ectopic pregnancies, and stillbirths $(0,1$, or $\geq 2)$; the status and timing of menopause (premenopausal, bilateral oophorectomy before natural menopause [yes or no], hysterectomy without bilateral oophorectomy or with missing data on the number of the removal of ovary before natural menopause [yes or no], or natural menopause at age $\geq 50$, 45-49, or $<45$ ); oophorectomy at age $\leq 50$ (no, unilateral, or bilateral); the use of oral contraceptives (never, $<12,12-23$, or $\geq 24$ months); and the use of hormone replacement therapy (HRT) (yes or no). Finally, multivariable logistic models for the association of $\mathrm{HCC}$ with age at menarche, number of FTP, number of failed pregnancies, and HRT use were further adjusted for the status and timing of menopause. Models evaluating the effects of age at natural menopause and oophorectomy at age $\leq 50$ were further adjusted for the use of HRT. In assessing the effect of oral contraceptive use, we further adjusted for the number of FTP.

Categorical trends were tested in logistic regression by using an ordered categorical variable. To evaluate the potential etiologic differences between patients with and without chronic hepatitis $B$, we conducted analyses stratified by the status of HBsAg. Statistical significance of the modification effect of $\mathrm{HBsAg}$ status on the HCC risk associated with each reproductive factor was determined by comparing the fit of the logistic model that included the main effects and all potential confounders with a fully parameterized model containing all possible 2-factor interaction terms for the variables of interest. All statistical tests were 2-sided.

\section{Results}

The distributions of selected characteristics among the 218 cases, 565 women at high risk of HCC because of a first-degree-relative family history of HCC, and 164 spouse controls are shown in Table 1 . The mean age of the subjects at recruitment showed cases (mean, 58.5 years; range, 37-77 years) to be older than the controls (women at high risk: mean, 50.5 years; spouse controls: mean, 49.3 years; range, 35-79 years for all control women). Cases were also more likely to have a higher body mass index and a history of diabetes mellitus than the two groups of controls.

Among the 209 cases with available data on $\mathrm{HBsAg}, 91$ (43.5\%) were positive for HBsAg. Ninety-four (83.9\%) of the $112 \mathrm{HBsAg}$-negative cases with known status of anti-HCV tested positive for anti-HCV. Only 18 of these $\mathrm{HBsAg-negative} \mathrm{patients} \mathrm{were} \mathrm{also} \mathrm{negative} \mathrm{for} \mathrm{anti-HCV}$ (data not shown). Cases and the women at high risk had a similar HBsAg-positive rate, as was expected because of intrafamilial transmission of HBV during early childhood. ${ }^{38}$ Their HBsAg-positive rates were higher than those of the spouse controls (19.6\%), in which the HBsAg carrier rate was similar to that reported in the general population in Taiwan. ${ }^{34}$ Also, anti-HCV positivity was more prevalent in cases than in the two groups of controls.

The control women at high-risk of HCC and spouse control subjects were similar in all the characteristics listed in Table 1 except for $\mathrm{HBsAg}$ positivity. To gain statistical power and precision for estimation of the ORs, we thereafter combined the 2 groups of controls in the following analyses performed to assess the effect of reproductive factors on HCC risk. After adjustment for age at recruitment, history of diabetes, and the status and timing of menopause, age at menarche was inversely associated with risk of HCC in a dose-response manner $\left(P_{\text {trend }}=.0059\right)$. Women who began menstruation at age 12 or younger had a multivariate-adjusted OR of 2.65 (95\% CI, 1.275.52) relative to those who began menstruation after age 15. There was a decreasing trend in HCC risk with increasing number of FTP $\left(P_{\text {trend }}=.0216\right)$. The multivariate-adjusted $\mathrm{OR}$ for women with 4 or more FTPs versus those with 0 or 1 FTP was 0.45 (95\% CI, 0.24-0.84). The number of failed pregnancies seemed not to be associated with risk (Table 2).

Oophorectomy at age $\leq 50$ during the reproductive period was associated with increased risk of HCC after adjustment for age at recruitment, history of diabetes, and HRT use (multivariate-adjusted OR, 2.57; 95\% CI, 1.42-4.63), but a trend with the number of the removal of ovaries was not apparent. Among women aged 45 to 55 
Table 1. Distribution of Selected Characteristics Among Patients With HCC and Control Women

\begin{tabular}{|c|c|c|c|c|c|}
\hline Characteristic & $\begin{array}{l}\text { HCC Patients } \\
(\mathrm{n}=\mathbf{2 1 8})\end{array}$ & $\begin{array}{c}\text { Women at } \\
\text { High Risk } \\
(\mathrm{n}=565)\end{array}$ & $\begin{array}{l}\text { Spouse Controls } \\
\quad(n=164)\end{array}$ & $\begin{array}{l}\text { Women at High Risk } \\
\text { Versus Spouse }(P)\end{array}$ & $\begin{array}{l}\text { HCC Versus All } \\
\text { Controls }(P)\end{array}$ \\
\hline Age $(y)$, mean $\pm S D$ & $58.5 \pm 8.9$ & $50.5 \pm 10.8$ & $49.3 \pm 8.7$ & .1743 & .0001 \\
\hline History of diabetes (\%) & 18.8 & 5.0 & 6.1 & .563 & .001 \\
\hline $\begin{array}{l}\text { Body mass index }\left(\mathrm{kg} / \mathrm{m}^{2}\right) \text {, mean } \pm \text { SD } \\
\text { Missing }\end{array}$ & $\begin{array}{l}24.1 \pm 3.9 \\
\quad 22\end{array}$ & $\begin{array}{c}23.3 \pm 3.7 \\
30\end{array}$ & $\begin{array}{c}22.9 \pm 2.9 \\
6\end{array}$ & .1402 & .0012 \\
\hline Cigarette smoking (\%) & 6.0 & 4.8 & 1.8 & .094 & .25 \\
\hline Alcohol consumption (\%) & 4.1 & 3.9 & 2.4 & .376 & .7 \\
\hline HBsAg (\% positivity) & 43.5 & 40.5 & 19.6 & .001 & .042 \\
\hline Missing & 9 & 2 & 1 & & \\
\hline Anti-HCV (\% positivity) & 56.4 & 3.6 & 3.1 & .765 & .001 \\
\hline Missing & 14 & 2 & 1 & & \\
\hline Age at menarche (y) (\%) & & & & .418 & .944 \\
\hline$\geq 16$ & 32.4 & 29.4 & 35.4 & & \\
\hline $14-15$ & 44.1 & 44.1 & 43.3 & & \\
\hline 13 & 16.9 & 19.0 & 15.2 & & \\
\hline$\leq 12$ & 6.6 & 7.5 & 6.1 & & \\
\hline Missing & 5 & 7 & 0 & & \\
\hline No. of FTP (mean \pm SD) & $3.7 \pm 2.0$ & $3.1 \pm 1.8$ & $3.1 \pm 1.4$ & .4727 & .0001 \\
\hline Missing & 2 & 2 & 1 & & \\
\hline With failed pregnancies (\%) & 20.8 & 19.3 & 20.2 & .794 & .674 \\
\hline Missing & 2 & 1 & 1 & & \\
\hline Postmenopausal (\%) & 84.8 & 46.3 & 44.5 & .690 & .001 \\
\hline Missing & 1 & 1 & 0 & & \\
\hline $\begin{array}{l}\text { Age at natural menopause }(y) \\
\text { mean } \pm \text { SD }\end{array}$ & $49.8 \pm 4.4$ & $49.8 \pm 3.6$ & $49.5 \pm 4.0$ & .5673 & .990 \\
\hline $\begin{array}{l}\text { History of oophorectomy } \leq 50 \text { y before } \\
\text { the natural menopause }(\%)\end{array}$ & 10.6 & 5.3 & 3.7 & .39 & .003 \\
\hline Unilateral (\%) & 4.2 & 2.9 & 1.8 & .589 & .24 \\
\hline Bilateral (\%) & 5.6 & 2.0 & 1.2 & .743 & .003 \\
\hline Missing & 2 & 3 & 1 & & \\
\hline Contraceptive use (\%) & 9.2 & 15.4 & 14.0 & .665 & .026 \\
\hline$\geq 24$ months & 1.8 & 6.4 & 6.1 & .883 & .009 \\
\hline Missing & 1 & 4 & 0 & & \\
\hline HRT use (\%) & 10.1 & 14.0 & 11.6 & .428 & .192 \\
\hline$>36$ months & 1.4 & 2.8 & 3.0 & .797 & .219 \\
\hline Missing & 2 & 2 & 0 & & \\
\hline
\end{tabular}

NOTE. Number of failed pregnancies was calculated as number of miscarriages, ectopic pregnancies, or stillbirths.

years who had no history of surgical menopause, there was an increasing trend in risk of HCC with decreasing age at natural menopause after adjustment for age at recruitment, history of diabetes, and HRT use (multivariateadjusted ORs for women having natural menopause at age $\geq 50,45-49$, and $<45$ compared with premenopausal women were 1.46 [95\% CI, 0.52-4.08], 2.14 [95\% CI, 0.80-5.73], and 4.27 [95\% CI, 1.01-18.07], respectively; $\left.P_{\text {trend }}=.0251\right)($ Table 3$)$.

We found an inverse association between use of oral contraceptives and HCC when adjusted only for age at recruitment and history of diabetes, with use for 24 or more months associated with an OR of 0.35 (95\% CI, 0.12-0.99) relative to never-users. After further controlling for confounding by the number of FTP, the strength of this association still approached statistical significance (multivariate-adjusted OR, 0.38; 95\% CI, 0.13-1.09; $P=.0726)$. Use of HRT was associated with a low rela- tive risk for HCC. This association became statistically significant after adjustment for the status and timing of menopause (multivariate-adjusted OR, 0.46; 95\% CI, 0.27-0.79). There was also a decreasing trend in HCC risk with increasing duration of HRT use $\left(P_{\text {trend }}=\right.$ .0013). The multivariate-adjusted OR for women who had used HRT for more than 36 months versus neverusers was 0.24 (95\% CI, 0.07-0.84) (Table 4).

For all reproductive factors except 1 , no evidence for the heterogeneity in the ORs calculated separately among $\mathrm{HBsAg}$ carriers and noncarriers was found (Tables 2 through 4). The exception was early onset of menarche ( $\leq 12$ years), which increased HCC risk among HBsAg carriers (multivariate-adjusted OR, 6.96; 95\% CI, 2.5219.18) but posed no increased risk among HBsAg noncarriers. The difference in this association between HBsAg carriers and noncarriers was statistically significant $\left(P_{\text {interaction }}=.0053\right)($ Table 2$)$. 
Table 2. Adjusted ORs for Association of Age at Menarche, Number of FTP, and Number of Failed Pregnancies With HCC*

\begin{tabular}{|c|c|c|c|c|c|}
\hline \multirow[b]{2}{*}{ Variable } & \multirow{2}{*}{$\begin{array}{c}\text { No. of } \\
\text { Case/Control }\end{array}$} & \multicolumn{2}{|c|}{ All Study Subjects } & \multirow{2}{*}{$\begin{array}{c}\text { HBsAg-Positive } \\
\text { OR‡ (95\% Cl) }\end{array}$} & \multirow{2}{*}{$\begin{array}{l}\text { HBsAg-Negative } \\
\text { OR‡ (95\% CI) }\end{array}$} \\
\hline & & OR1† (95\% Cl) & OR2‡ (95\% Cl) & & \\
\hline \multicolumn{6}{|c|}{ Age at menarche $(\mathrm{y})$} \\
\hline$\geq 16$ & $69 / 222$ & 1.00 (Referent) & $1.00 \S$ (Referent) & $1.00 \|$ | (Referent) & 1.00 (Referent) \\
\hline $14-15$ & $94 / 317$ & $1.47(0.99-2.18)$ & $1.42(0.96-2.12)$ & $2.24(1.15-4.39)$ & $1.08(0.64-1.82)$ \\
\hline 13 & $36 / 131$ & $1.62(0.97-2.71)$ & $1.61(0.96-2.72)$ & $2.31(0.97-5.50)$ & $1.26(0.62-2.56)$ \\
\hline$\leq 12$ & $14 / 52$ & $2.36(1.15-4.81)$ & $2.65(1.27-5.52)$ & $6.96(2.52-19.18)$ & $0.59(0.12-2.84)$ \\
\hline Missing & $5 / 7$ & & & & \\
\hline \multicolumn{6}{|l|}{ No. of FTP } \\
\hline$\leq 1$ & $24 / 79$ & 1.00 (Referent) & 1.00\# (Referent) & 1.00 (Referent) & 1.00 (Referent) \\
\hline 2 & $33 / 213$ & $0.61(0.33-1.13)$ & $0.60(0.32-1.14)$ & $0.68(0.26-1.73)$ & $0.73(0.27-1.96)$ \\
\hline 3 & $53 / 205$ & $0.62(0.34-1.11)$ & $0.55(0.30-1.03)$ & $0.71(0.30-1.71)$ & $0.46(0.18-1.22)$ \\
\hline$\geq 4$ & $106 / 229$ & $0.46(0.25-0.85)$ & $0.45(0.24-0.84)$ & $0.46(0.18-1.16)$ & $0.42(0.16-1.09)$ \\
\hline Missing & $2 / 3$ & & & & \\
\hline \multicolumn{6}{|c|}{ No. of failed pregnancies } \\
\hline 0 & $171 / 585$ & 1.00 (Referent) & 1.00 (Referent) & 1.00 (Referent) & 1.00 (Referent) \\
\hline 1 & 36/106 & $1.01(0.64-1.57)$ & $1.02(0.65-1.60)$ & $1.05(0.51-2.16)$ & $1.00(0.54-1.85)$ \\
\hline$\geq 2$ & $9 / 36$ & $0.58(0.26-1.30)$ & $0.65(0.29-1.48)$ & $0.87(0.21-3.55)$ & $0.64(0.23-1.77)$ \\
\hline Missing & $2 / 2$ & & & & \\
\hline
\end{tabular}

NOTE. Number of failed pregnancies was calculated as number of miscarriages, ectopic pregnancies, or stillbirths.

*Information was missing for status of HBsAg for 9 cases and 3 controls, status of menopause for 1 case and 1 control, and type or age of menopause for 2 cases and 3 controls.

†Adjusted for age at recruitment (continuous variable) and history of diabetes.

$\ddagger$ Adjusted for age at recruitment (continuous variable), history of diabetes, and status, type, and age of menopause (premenopausal, bilateral oophorectomy before the natural menopause [yes or no], hysterectomy without bilateral oophorectomy or with missing data on the number of the removal of ovary before natural menopause [yes or no], or natural menopause at age $\geq 50,45-49$, or $<45$ ).

$\S P_{\text {trend }}=.0059$.

|Test for OR homogeneity across status of HBsAg: $\chi^{2}(\mathrm{df}=3)=12.706, P=.0053$.

$\mathbb{q} P_{\text {trend }}=.0004$.

$\# P_{\text {trend }}=.0216$.

Only 5 controls related to the cases were included in this study. The results did not change after exclusion of the 5 controls.

\section{Discussion}

A relationship between $\mathrm{HCC}$ and reproductive factors, which modify endogenous levels of female hormones, has been hypothesized but not extensively studied. ${ }^{17}$ In this study, the HCC risk was inversely related to the age at natural menopause. Oophorectomy performed at age 50 or younger during premenopausal years was also a risk factor for HCC. This result is compatible with the enhancing effect of ovariectomy on hepatocarcinogenesis in animal experiments. ${ }^{11,16}$ Pregnancy, which increases serum estrogen levels about 100 -fold, ${ }^{39}$ was found to exert a protective effect against HCC, and the protection increased with the number of FTP. To our knowledge, no studies of postmenopausal estrogen replacement therapy and HCC have yet been conducted. After adjustment for the status and timing of menopause, we found that the risk of HCC was low among ever-users of HRT compared with never-users, and the risk decreased linearly with increasing duration of use. Combined with the striking male-to-female ratio in the incidence of HCC observed in different populations ${ }^{1,2}$ and in various animal models, ${ }^{9-15}$ these results suggest that higher exposure to estrogen may be protective against HCC.

Cases in this study were all drawn from hospitals. The ideal control group might be those who would be treated at the same hospital if they developed HCC. We thus selected controls from relatives of HCC patients who were treated at the same hospital during the same period as the case subjects included in the analysis. Although selection bias may occur because exposure more common to cases may become overrepresented in their relatives, this would only result in underestimating the ORs.

Our finding of an inverse association between the number of FTPs and HCC is in contrast to the results of a prior Italian case-control study involving only 79 cases, in which parous women were at a higher risk than nulliparous women. ${ }^{17}$ On the other hand, our result of a marginally statistically significant inverse relationship between oral contraceptive use and HCC is not compatible with the results of 6 case-control studies with information on the duration of oral contraceptive use conducted among white women in low and intermediate risk areas, in which the risk of HCC was increased among users of oral contraceptives, particularly for women with 
Table 3. Adjusted ORs of the Relationship Between Natural or Artificial Menopause and HCC*

\begin{tabular}{|c|c|c|c|c|c|}
\hline \multirow[b]{2}{*}{ Variable } & \multirow{2}{*}{$\begin{array}{c}\text { No. of } \\
\text { Case/Control }\end{array}$} & \multicolumn{2}{|c|}{ All Study Subjects } & \multirow{2}{*}{$\begin{array}{l}\text { HBsAg-Positive } \\
\text { OR‡ (95\% CI) }\end{array}$} & \multirow{2}{*}{$\begin{array}{c}\text { HBsAg-Negative } \\
\text { OR‡ (95\% CI) }\end{array}$} \\
\hline & & OR1† (95\% CI) & OR2 $¥(95 \% \mathrm{Cl})$ & & \\
\hline \multicolumn{6}{|l|}{ Natural menopausal status $\S$} \\
\hline Premenopausal & $19 / 146$ & 1.00 (Referent) & 1.00|| (Referent) & 1.00 (Referent) & 1.00 (Referent) \\
\hline Postmenopausal & $24 / 74$ & $1.99(0.90-4.43)$ & $2.08(0.93-4.66)$ & $2.21(0.73-6.69)$ & $1.74(0.46-6.63)$ \\
\hline Status unknown & $0 / 1$ & & & & \\
\hline \multicolumn{6}{|l|}{ Age at natural menopause $(y)$} \\
\hline$\geq 50$ & $11 / 37$ & $1.51(0.54-4.22)$ & $1.46(0.52-4.08)$ & $1.62(0.32-8.10)$ & $1.23(0.25-6.18)$ \\
\hline $45-49$ & $9 / 31$ & $1.89(0.73-4.86)$ & $2.14(0.80-5.73)$ & $2.57(0.64-10.23)$ & $1.44(0.28-7.49)$ \\
\hline$<45$ & $4 / 6$ & $4.04(0.97-16.88)$ & $4.27(1.01-18.07)$ & $2.72(0.21-35.12)$ & $6.05(0.77-47.34)$ \\
\hline \multicolumn{6}{|l|}{ Oophorectomy $\leq 50$ y } \\
\hline No & $195 / 693$ & 1.00 (Referent) & 1.00 (Referent) & 1.00 (Referent) & 1.00 (Referent) \\
\hline Yes & 23/36 & $2.27(1.27-4.04)$ & $2.57(1.42-4.63)$ & $1.58(0.63-3.96)$ & $3.86(1.75-8.52)$ \\
\hline Unilateral & $9 / 19$ & $2.44(1.05-5.64)$ & $2.67(1.15-6.20)$ & $1.96(0.62-6.19)$ & $3.85(1.11-13.38)$ \\
\hline Bilateral & $12 / 13$ & $2.33(1.01-5.41)$ & $2.69(1.14-6.35)$ & $1.18(0.21-6.59)$ & $4.01(1.42-11.30)$ \\
\hline $\begin{array}{l}\text { Missing data on the no. or } \\
\text { the removal of ovary }\end{array}$ & $2 / 4$ & & & & \\
\hline
\end{tabular}

*Information was missing for status of HBsAg for 9 cases and 3 controls.

†Adjusted for age at recruitment (continuous variable) and history of diabetes.

$\ddagger$ Adjusted for age at recruitment (continuous variable), history of diabetes, and use of HRT (yes or no).

§Among women aged 45-55 years at recruitment who had no history of surgical menopause.

$\|$ Compared with premenopausal women, $P_{\text {trend }}=.0251$ for women having natural menopause at age $\geq 50,45-49$, and $<45$.

duration of oral contraceptive use longer than 5 years. ${ }^{3,21-25}$ However, the sample size in each of these studies was small, containing only 9 to 26 cases. $^{3,21-25}$ Otherwise, these studies did not take additional reproductive factors into account, so distortion of the relative risk estimate is possible. In fact, 2 studies involving a larger number of cases that included women in regions endemic for HBV infection and HCC found a statistically nonsignificant decreased risk of HCC for use of oral contraceptives. ${ }^{26,27}$

The effect of exogenous estrogen use on the reduction in HCC risk observed in this study is consistent with the

Table 4. Adjusted ORs for Association of Use of Oral Contraceptives or HRT with HCC*

\begin{tabular}{|c|c|c|c|c|c|}
\hline \multirow[b]{2}{*}{ Variable } & \multirow{2}{*}{$\begin{array}{c}\text { No. of } \\
\text { Case/Control }\end{array}$} & \multicolumn{2}{|c|}{ All Study Subjects } & \multirow{2}{*}{$\begin{array}{c}\text { HBsAg-Positive } \\
\text { OR (95\% CI) }\end{array}$} & \multirow{2}{*}{$\begin{array}{c}\text { HBsAg-Negative } \\
\text { OR }(95 \% \mathrm{CI})\end{array}$} \\
\hline & & OR1† (95\% CI) & OR2 (95\% Cl) & & \\
\hline \multicolumn{6}{|l|}{ Use of oral contraceptive } \\
\hline Never & $198 / 619$ & 1.00 (Referent) & $1.00 \ddagger$ (Referent) & $1.00 \ddagger$ (Referent) & $1.00 \ddagger$ (Referent) \\
\hline Ever & 20/110 & $0.71(0.42-1.20)$ & $0.75(0.44-1.28)$ & $0.54(0.23-1.29)$ & $0.98(0.48-1.99)$ \\
\hline \multicolumn{6}{|l|}{ Duration (month) } \\
\hline$<12$ & $7 / 33$ & $0.90(0.37-2.14)$ & $0.92(0.38-2.24)$ & $0.75(0.20-2.84)$ & $1.15(0.34-3.88)$ \\
\hline $12-23$ & $8 / 27$ & $1.04(0.45-2.45)$ & $1.12(0.48-2.64)$ & $0.46(0.10-2.20)$ & $1.67(0.53-5.27)$ \\
\hline$\geq 24$ & $4 / 46$ & $0.35(0.12-0.99)$ & $0.38(0.13-1.09)$ & $0.53(0.11-2.50)$ & $0.38(0.09-1.67)$ \\
\hline Duration unknown & $1 / 4$ & & & & \\
\hline \multicolumn{6}{|l|}{ Use of HRT } \\
\hline Never & 196/631 & 1.00 (Referent) & $1.00 \S \|$ (Referent) & $1.00 \S$ (Referent) & $1.00 \S \rrbracket$ (Referent) \\
\hline Ever & 22/98 & $0.64(0.39-1.06)$ & $0.46(0.27-0.79)$ & $0.62(0.26-1.47)$ & $0.41(0.20-0.83)$ \\
\hline \multicolumn{6}{|l|}{ Duration (month) } \\
\hline$\leq 12$ & $11 / 45$ & $0.77(0.38-1.57)$ & $0.60(0.29-1.23)$ & $0.70(0.23-2.13)$ & $0.54(0.19-1.54)$ \\
\hline$>12$ and $\leq 36$ & $6 / 30$ & $0.53(0.21-1.32)$ & $0.36(0.14-0.91)$ & $0.23(0.03-1.90)$ & $0.47(0.16-1.40)$ \\
\hline$>36$ & $3 / 21$ & $0.35(0.10-1.21)$ & $0.24(0.07-0.84)$ & $0.70(0.13-3.82)$ & $0.10(0.01-0.84)$ \\
\hline Duration unknown & $2 / 2$ & & & & \\
\hline
\end{tabular}

*Information was missing for status of HBsAg for 9 cases and 3 controls, status of menopause for 1 case and 1 control, type or age of menopause for 2 cases and 3 controls, and number of FTP for 2 cases and 3 controls.

†Adjusted for age at recruitment (continuous variable) and history of diabetes.

$\ddagger$ Adjusted for age at recruitment (continuous variable), history of diabetes, and number of FTP $(\leq 1,2,3$, or $\geq 4$ ).

$\S$ Adjusted for age at recruitment (continuous variable), history of diabetes, and status, type, and age of menopause (premenopausal, bilateral oophorectomy before the natural menopause [yes or no], hysterectomy without bilateral oophorectomy or with missing data on the number of the removal of ovary before natural menopause [yes or no], or natural menopause at age $\geq 50,45-49$, or $<45$ ).

$\|$ Compared with never-users, $P_{\text {trend }}=.0013$ for ever-users with duration of use $\leq 12,>12$ and $\leq 36$, and $>36$ months.

ๆCompared with never-users, $P_{\text {trend }}=.0060$ for ever-users with duration of use $\leq 12,>12$ and $\leq 36$, and $>36$ months. 
treatment effect of various synthetic forms of estrogens on hepatocarcinogenesis in some animal models, ${ }^{16,28,32,33}$ but is opposite to others. ${ }^{29-31}$ However, it should be noted that oral contraceptive steroids administered in animal studies that suggested estrogens as promoters of hepatocarcinogenesis were usually given at a very high dose (between 6 to 200 times the human dose). ${ }^{29-31}$ Indeed, longterm treatment with oral contraceptive steroids at nonhepatotoxic doses in animals was found to inhibit basal and induced hepatocyte proliferation. ${ }^{32}$

It is not known why increased exposure to estrogen may lower HCC risk, but experimental data suggest that estrogen can induce expression of certain tumor suppressor genes. ${ }^{40,41}$ Otherwise, estradiol is catabolized mainly by hydroxylation reaction. Its 2-hydroxy metabolite can be converted to 2-methoxyestradiol by catechol O-methyltransferase, an enzyme with high levels in the liver. ${ }^{42}$ 2-Methoxyestradiol has been shown to induce apoptosis, inhibit angiogenesis, and suppress tumor growth in vitro and in vivo. 43

Although several factors related to higher exposure to estrogen during adulthood seemed to be associated with decreased risk of HCC in this study regardless of HBsAg carrier status, an early menarche was associated with elevated disease risk among HBV carrier women. The mechanism of age at menarche involvement in the genesis of HBV-related HCC remains to be elucidated. However, this might be related to the effect of estrogen on immune function and the natural course of chronic HBV infection. ${ }^{38,44-46}$

The major route of acquiring chronic HBV infection in Taiwan is through mother-to-child vertical transmission of this virus, ${ }^{38}$ whereas transmission of $\mathrm{HCV}$ is primarily through blood contact. ${ }^{2}$ Chronic infection with HBV proceeds through 3 phases: a high replicative phase, followed by the immune clearance phase marked by cellmediated immune response, and then the low replicative phase. The first phase covers an average period of 15 to 20 years, during which there is active replication of HBV. After this period, less efficient viral replication occurs. ${ }^{38,44}$ Estrogen suppresses B lymphopoiesis. ${ }^{45}$ It has also been documented that HRT modulates levels of certain cytokines. ${ }^{46}$ As such, early estrogen exposure resulting from the early onset of menarche could potentially influence the replication activity of $\mathrm{HBV}$ at early ages, causing various degrees of hepatic lesions, including chronic hepatitis and cirrhosis, which are closely associated with the subsequent risk of developing HCC. ${ }^{38,44}$ However, estrogen might suppress the growth of HCC and/or the regenerative nodule, which is the most important preneoplastic lesion of HCC, ${ }^{47}$ in cirrhotic patients. ${ }^{43}$
In conclusion, our observations of a relation between HCC and several reproductive events that are thought to reflect cumulative exposure to estrogen provide indirect evidence supporting a role for estrogen in HCC development. There is mounting evidence that hormonal secretion and metabolism are largely genetically regulated. Several polymorphic genes involved in estrogen metabolism have been identified. ${ }^{48}$ Incorporation of these genetic markers in future studies may provide additional insight into the molecular mechanism of estrogen involvement in human hepatocarcinogenesis. On the other hand, although our data suggest that longer use of HRT may be protective against HCC, the impact of the formulation and treatment schedule of use could not be analyzed because no such information was collected. It will be particularly important to address this issue in additional studies with a larger sample size, given the widespread use of HRT.

\section{References}

1. Chen CJ, Yu MW, Liaw YF. Epidemiological characteristics and risk factors of hepatocellular carcinoma. J Gastroenterol Hepatol 1997;12:S294308.

2. Yu MW, Chen CJ. Hepatitis B and C viruses in the development of hepatocellular carcinoma. Crit Rev Oncol Hematol 1994;17:71-91.

3. Yu MC, Tong MJ, Govindarajan S, Henderson BE. Nonviral risk factors for hepatocellular carcinoma in a low-risk population, the Non-Asians of Los Angeles County, California. J Natl Cancer Inst 1991;83:1820-1826.

4. Yu MW, Hsu FC, Sheen IS, Chu CM, Lin DY, Chen CJ, Liaw YF. Prospective study of hepatocellular carcinoma and liver cirrhosis in asymptomatic chronic hepatitis B virus carriers. Am J Epidemiol 1997;145:10391047.

5. Eisenfeld AJ, Aten RF, Weinberger M, Haselbacher G, Halpern K, Krakoff L. Estrogen receptor in the mammalian liver. Science 1976;191:862-865.

6. Aten RF, Dickson RB, Eisenfeld AJ. Estrogen receptor in adult male rat liver. Endocrinology 1978;103:1629-1635.

7. Nagasue N, Kohno H, Chang YC, Hayashi T, Utsumi Y, Nakamura T, Yukaya H. Androgen and estrogen receptors in hepatocellular carcinoma and the surrounding liver in women. Cancer 1989;63:112-116.

8. Ohnishi S, Murakami T, Moriyama T, Mitamura K, Imawari M. Androgen and estrogen receptors in hepatocellular carcinoma and in the surrounding noncancerous liver tissue. HEPATOLOGY 1986;6:440-443.

9. Toh YC. Effect of neonatal castration on liver tumor induction by N-2fluorenylacetamide in suckling BALB/c mice. Carcinogenesis 1981;2: 1219-1221

10. Firminger HI, Reuber MD. Influence of adrenocortical, androgenic, and anabolic hormones on the development of carcinoma and cirrhosis of the liver in AXC rats fed N-2-fluorenyldiacetamide. J Natl Cancer Inst 1961; 27:559-595.

11. Vesselinovitch SD, Itze L, Mihailovich N, Rao KV. Modifying role of partial hepatectomy and gonadectomy in ethylnitrosourea-induced hepatocarcinogenesis. Cancer Res 1980;40:1538-1542.

12. Kemp CJ, Leary CN, Drinkwater NR. Promotion of murine hepatocarcinogenesis by testosterone is androgen receptor-dependent but not cell autonomous. Proc Natl Acad Sci U S A 1989;86:7505-7509.

13. Dunsford HA, Sell S, Chisari FV. Hepatocarcinogenesis due to chronic liver cell injury in hepatitis B virus transgenic mice. Cancer Res 1990;50: 3400-3407.

14. Kim CM, Koike K, Saito I, Miyamura T, Jay G. HBx gene of hepatitis B virus induces liver cancer in transgenic mice. Nature 1991;351:317-320. 
15. Moriya K, Fujie H, Shintani Y, Yotsuyanagi H, Tsutsumi T, Ishibashi K, Matsuura $\mathrm{Y}$, et al. The core protein of hepatitis $\mathrm{C}$ virus induces hepatocellular carcinoma in transgenic mice. Nat Med 1998;4:1065-1067.

16. Nakatani T, Roy G, Fujimoto N, Asahara T, Ito A. Sex hormone dependency of diethylnitrosamine-induced liver tumors in mice and chemoprevention by leuprorelin. Jpn J Cancer Res 2001;92:249-256.

17. La Vecchia C, Negri E, Franceschi S, D’Avanzo B. Reproductive factors and the risk of hepatocellular carcinoma in women. Int J Cancer 1992;52: 351-354.

18. Yu MW, Yang YC, Yang SY, Cheng SW, Liaw YF, Lin SM, Chen CJ. Hormonal markers and hepatitis B virus-related hepatocellular carcinoma risk: a nested case-control study among men. J Natl Cancer Inst 2001;93: 1644-1651.

19. Tanaka K, Sakai H, Hashizume M, Hirohata T. Serum testosterone: estradiol ratio and the development of hepatocellular carcinoma among male cirrhotic patients. Cancer Res 2000;60:5106-5110.

20. Goldfarb S. Sex hormones and hepatic neoplasia. Cancer Res 1976;36: 2584-2588.

21. Henderson BE, Preston-Martin S, Edmondson HA, Peters RL, Pike MC. Hepatocellular carcinoma and oral contraceptives. Br J Cancer 1983;48: 437-440.

22. Palmer JR, Rosenberg L, Kaufman DW, Warshauer ME, Stolley P, Shapiro S. Oral contraceptive use and liver cancer. Am J Epidemiol 1989;130: 878-882.

23. Neuberger J, Forman D, Doll R, Williams R. Oral contraceptives and hepatocellular carcinoma. Br Med J 1986;292:1355-1357.

24. Forman D, Vincent TJ, Doll R. Cancer of the liver and the use of oral contraceptives. Br Med J 1986;292:1357-1361.

25. La Vecchia C, Negri E, Prazzini F. Oral contraceptives and primary liver cancer. Br J Cancer 1989;59:460-461.

26. The WHO Collaborative Study of Neoplasia and Steroid Contraceptives. Combined oral contraceptives and liver cancer. Int J Cancer 1989;43:254259.

27. Kew MC, Song E, Mohammed A, Hodkinson J. Contraceptive steroids as a risk factor for hepatocellular carcinoma: a case/control study in South African black women. Hepatology 1990;11:298-302.

28. Mishkin SY, Farber E, Ho RK, Mulay S, Mishkin S. Evidence for the hormone dependency of hepatic hyperplastic nodules: inhibition of malignant transformation after exogenous $17 \beta$-estradiol and tamoxifen. HEPATOLOGY 1983;3:308-316.

29. Taper HS. The effect of estradiol-17-phenylpropionate and estradiol benzoate on $\mathrm{N}$-nitrosomorpholine-induced liver carcinogenesis in ovariectomized female rats. Cancer 1978;42:462-467.

30. Yager JD Jr, Yager R. Oral contraceptive steroids as promoters of hepatocarcinogenesis in female Sprague-Dawley rats. Cancer Res 1980;40:36803685.

31. Cameron RG, Imaida K, Tsuda H, Ito N. Promotive effects of steroids and bile acids on hepatocarcinogenesis initiated by diethylnitrosamine. Cancer Res 1982;42:2426-2428.
32. Yager JD, Zurlo J, Sewall CH, Lucier GW, He H. Growth stimulation followed by growth inhibition in livers of female rats treated with ethinyl estradiol. Carcinogenesis 1994;15:2117-2123.

33. Shimizu I, Yasuda M, Mizobuchi Y, Ma YR, Liu F, Shiba M, Horie T, et al. Suppressive effect of estradiol on chemical hepatocarcinogenesis in rats. Gut 1998;42:112-119.

34. Yu MW, You SL, Chang AS, Lu SN, Liaw YF, Chen CJ. Association between hepatitis $C$ virus antibodies and hepatocellular carcinoma in Taiwan. Cancer Res 1991;51:5621-5625.

35. Yu MW, Cheng SW, Lin MW, Yang SY, Liaw YF, Chang HC, Hsiao TJ, et al. Androgen-receptor gene CAG repeats, plasma testosterone levels, and risk of hepatitis B-related hepatocellular carcinoma. J Natl Cancer Inst 2000;92:2023-2028.

36. Collaborative Group on Hormonal Factors in Breast Cancer. Breast cancer and hormone replacement therapy: collaborative reanalysis of data from 51 epidemiological studies of 52,705 women with breast cancer and 108,411 women without breast cancer. Lancet 1997;350:1047-1059.

37. Troisi R, Potischman N, Hoover RN, Siiteri P, Brinton LA. Insulin and endometrial cancer. Am J Epidemiol 1997;146:476-482.

38. Chen DS. From hepatitis to hepatoma: lessons from type B viral hepatitis. Science 1993;262:369-370.

39. Yen SS. Endocrinology of pregnancy. In: Creasy RK, Resnik R, eds. Maternal-Fetal Medicine: Principles and Practice. 3rd ed. Philadelphia: Saunders; 1994:382-412.

40. Marquis ST, Rajan JV, Wynshaw-Boris A, Xu J, Yin GY, Abel KJ, Weber $\mathrm{BL}$, et al. The developmental pattern of BRCA1 expression implies a role in differentiation of the breast and other tissues. Nat Genet 1995;11:17-26.

41. Hurd C, Khattree N, Dinda S, Alban P, Moudgil VK. Regulation of tumor suppressor proteins, p53 and retinoblastoma, by estrogen and antiestrogens in breast cancer cells. Oncogene 1997;15:991-995.

42. Mannisto PT, Ulmanen I, Lundstrom K, Taskinen J, Tenhunen J, Tilgmann C, Kaakkola S. Characteristics of catechol O-methyltransferase (COMT) and properties of selective COMT inhibitors. Prog Drug Res 1992;39:291-350.

43. Zhu BT, Conney AH. Is 2-methoxyestradiol and endogenous estrogen metabolite that inhibits mammary carcinogenesis? Cancer Res 1998;58: 2269-2277.

44. Chu CM. Towards control of hepatitis B in the Asia-Pacific region: natural history of chronic hepatitis $B$ virus infection in adults with emphasis on the occurrence of cirrhosis and hepatocellular carcinoma. J Gastroenterol Hepatol 2000;15(suppl):E25-30.

45. Medina KL, Strasser A, Kincade PW. Estrogen influences the differentiation, proliferation, and survival of early B-lineage precursors. Blood 2000; 95:2059-2067.

46. Cheleuitte D, Mizuno S, Glowacki J. In vitro secretion of cytokines by human bone marrow: effects of age and estrogen status. J Clin Endocrinol Metab 1998;83:2043-2051.

47. Theise ND. Cirrhosis and hepatocellular neoplasia: more like cousins than like parent and child. Gastroenterology 1996;111:526-528.

48. Clemons M, Goss P. Estrogen and the risk of breast cancer. N Engl J Med 2001;344:276-285. 